\title{
Parenting Stress and Coping Capacity Linked with Quality of Life among Parents of Children with Autism Spectrum Disorder
}

\author{
Chowdhury $\mathrm{MSH}^{1}$, Islam $\mathrm{MZ}^{2}$, Bhuiyan $\mathrm{MR}^{3}$, Rafi $\mathrm{A}^{4}$, Kawsar $\mathrm{AA}^{5}$ \\ DOI: https://doi.org/10.3329/jafmc.v15i1.48642
}

\begin{abstract}
Introduction: Autism spectrum disorder (ASD) is prevalent globally. Fundamental impairment of communication and social interactions are common features of ASD children. Parents of autistic children experience parenting differently with severe physical and psychological problems involved and suffer from higher parenting stress which ultimately influence their quality of life. Empowering parents of children with autism for use of available social support, to get assistance of coping strategies and to promote self confidence of odd feelings are essential for enabling the parents to improve their quality of life by reducing theirstress.
\end{abstract}

Objectives: To assess the link of parenting stress and coping capacity with quality of life among the parents whose children suffer from autism spectrum disorder (ASD) and to help the government and relevant organizations take the required steps to improve the living conditions of the parents of children having ASD.

Materials and Methods: This cross-sectional study was executed from July 2016 to June 2017 among 175 parents whose children have autism spectrum disorder. Data were collected by in-person interview method with systematic random sampling followed by semi-structured questionnaire.

Results: Majority (48.6\%) of the parents were between 31 to 40 years of age and mean $( \pm S D)$ age of the parents was 37.75 \pm 8.04 with the range of $21-64$ years. Most $(53.7 \%)$ of the parents were female. Majority of the parents $(42.9 \%)$ were educated up to graduation level and $(72.0 \%)$ were service holders. Most $(93.1 \%)$ parents were from urban areas and $(92.6 \%)$ parents were represents from nuclear family. Majority parents (55.4\%) had 2 children and most $(70.9 \%)$ children have noticed their first symptom at the age of 2 and maximum $(47.4 \%)$ children were identified with ASD at three years of age. Maximum (62.9\%) family had monthly income of Tk. 20001-50000 and majority children $(77.1 \%)$ were diagnosed in different government hospitals.

Conclusion: Considering the fact that ASD is a mushrooming public health problem in Bangladesh, widespread prior diagnostic facilities are needed to be made available all over the country especially in peri-urban and urban areas, to measure the parenting stress and identify ways of coping capacity for improving lives of parents whose children have ASD.

Key-words: Autism spectrum disorder, Parenting stress, Coping capacity, Quality of life.

\section{Introduction}

Autism is not a curse for the society. Autism manifests itself in the initial three years of life and is a lifelong developmental disability. All regions of the world have high rate of autism and the impact on children, their families, communities and societies, is tremendous. Around 70 million individuals are affected by autism around the world ${ }^{1}$. To bring spotlight to the necessity of needing to improve the lives of children and adults who experience the hardships of this disorder, so that they can lead full lives, the United Nations General Assembly collectively announced 2 April as World Autism Awareness Day. A rough evaluation has been made that 1 percent of the total world's population endures the pain of autism spectrum disorder. That is, about 70 million people are affected by autism worldwide. Parents of autistic children experience live differently with severe physical and psychological problems involved and suffer from higher parenting stress which ultimately influence on their quality of life. Investigation of parenting stress is important as it provide a framework to identify the key variables that may contribute to the experience of related stress. Understanding what contributes to stress will then lead to more targeted interventions to support families and facilitate family functioning that may lead to improve the quality of their lives. Therefore it is valuable to pause and take stock of the current research on parenting stress and coping capacity focused on quality of life of parents of children with ASD. As there is no register of people with Autistic Disorder in Bangladesh, accurate incidence rates are not available. However, estimates based on the international screening studies can be done.

The most recent report provided by the $C D C$ revealed that autism spectrum disorder is identified in 1 out of 110 children in the United States, whereas Asia, Europe and North America have a much higher percentage ${ }^{2}$. Proper epidemiological survey programs are required to immediately address autism in Bangladesh since is it one of the most populated countries in the world. A study of 2013, utilizing community health workers, based on Bangladesh suggests that the prevalence of all kinds of neurodevelopmental disability is 7.1 percent. According to World Health Organization (WHO) the study for ASD, conducted in 2013, indicates a

1. Col Md Shakhawat Hossain Chowdhury, MBBS, MPH, MPhil, Assistant Director Medical Service, 7 Infantry Division, Sheikh Hasina Cantt, Barishal (E-mail: shakhawat_bosli@yahoo.com) 2. Professor Md. Ziaul Islam, MBBS, MPH, PGD, MSc, PhD, Professor \& Head, Department of Occupational and Environmental Health, NIPSOM, Mohakhali, Dhaka 3. Col Mhabubur Rahman Bhuiyan, MBBS, MPH, MBA, MPhil, Deputy Commandant, CMH, Dhaka 4. Col Ahmed Rafi, MBBS, MPH, MPhil, Commandant, Combined Military Hospital, Comilla 5. Dr Abdullah AI Kawsar, MBBS, MPH, MPhil, Medical officer, Lymchatic Filariasis Elimination and STH Control Program, CDC, DGHS, Mohakhali, Dhaka. 
prevalence of 0.15 percent, of which a 3 percent is in Dhaka city and 0.07 percent in the rural areas ${ }^{3}$.

In Bangladesh it has increased six fold over past decades ${ }^{1}$. While there is not exact data on the number of children being affected by autism in Bangladesh, it still is a neglected disease. According to a 2012 Daily Star report, about 1 percent from the 10 percent of the challenged people of this country are autistic which amounts to 1.5 lakh people 4 . A pilot study conducted in 2013 found that the prevalence ${ }^{5}$ of ASD in Bangladesh was $0.15 \%$ (3\% in Dhaka city and $0.07 \%$ in rural area). Regrettably, many developing countries including Bangladesh do not contain any data of the number of children or adults suffering from this lifelong enervating condition related to neurological development hence an urgent address of such scientific and medical questions are necessary ${ }^{3}$. Due to lack of awareness, people working with those families say 'myths and misconception' aggravate their sufferings ${ }^{6}$. There is a general negative attitude towards autism in the society. It is often regarded as a social barrier and even in this era of science and technology, the condition is considered to be a curse given by God. In many cases people believe children with autism are possession of devil power. The lack of knowledge is not prevalent among general people only. Cases of doctors misdiagnosing children and psychiatrists treating children with antipsychotic drugs clearly indicate the lack of knowledge in the field. There are not many schools for children with such conditions. Among the 20 schools of the country, all of them are located in the capital city of Dhaka?

\section{Materials and Methods}

This cross sectional study was carried out from July 2016 to June 2017 among 175 parents having children with autism spectrum disorder. Data were gathered from the parents of children both male and female with such condition, enrolled in different special schools around the city at the time of the data collection period. Children ranging from 3 to 18 years of age were a part of the study but seriously ill parents, children whose mother and/ father is/are not alive and any parent with psychological issue were excluded from the study. The research instrument was pretested on a total of 15 children with ASD. Before the conducting of the interviews with the mentioned children, an informed consent was received from the parents of the respondents. Systematic random sampling was the statistical technique used in the study. One twenty seven children were included from Proyash School, Institute of special education, Dhaka Cantonment; 24 children from Bangladesh Jatio Protibondhi Unnayan Foundation (JPUF), Mirpur Dhaka and 24 children were included from Autism Welfare Foundation Mohammadpur, Dhaka. To determine the level of parenting stress of the parents 'Parenting Stress Index Scale', to assess level of coping capacity of the parents to cope up stress, 'Stress coping resources inventory' and to assess the living conditions of the parents whose children have ASDs, 'Scoring domains of the WHOQOL-BREF' have been used. Data analysis was conducted by SPSS program using the computer.

\section{Results}

A socio-demogaphic distribution of the parents included in the study shows that the mean $( \pm S D)$ age of the parents was 37.75 \pm 8.04 years. Majority of the parents $94(53.7 \%)$ were female and $81(46.3 \%)$ were male and female male ratio was $1.16: 1$. The study initiated that maximum $164(93.7 \%)$ of the parents were
Muslim and only 11(6.3\%) were Hindu. According to education level majority of the $(42.9 \%)$ parents were educated up to graduation level followed by (31.4\%) masters, $(12.6 \%)$ higher secondary level and (13.1\%) secondary level of education. The study conveys that fathers of maximum children $(72.0 \%)$ were service holder followed by $(25.1 \%)$ businessman, $(1.1 \%)$ unemployed and $(1.7 \%)$ retired, whereas, mothers of majority children (83.43\%) were housewife followed by $(16.57 \%)$ service holder. Most $(93.1 \%)$ parents were from urban areas followed by $(6.9 \%)$ from peri-urban areas with $(92.6 \%)$ parents were from nuclear family and $(7.4 \%)$ were from joint family background. Among all the parents, majority (84.0\%) had family members of 2-4 and $(16.0 \%)$ had 5-7 family members. The mean $( \pm S D)$ of the family members was $3.85( \pm 0.81)$ with the range of family member 2-7. Majority parents (55.4\%) had 2 children, $(32.0 \%)$ had 1 children, (10.3\%) had 3 children and only (2.3\%) had 4 children, $(11.43 \%)$ parents had consanguineous marriage and the mean of the monthly household income was Tk. 49020.45 with standard deviation \pm 31872.11 and majority $(62.9 \%)$ family had monthly income Tk. 20001-50000 (Table-I).

According to socio-demographic characteristics of the children, age of the mother at child birth, majority $(56.6 \%)$ mothers were in $20-29$ years age group followed by $(24.0 \%)$ in $30-40$ years and $(19.4 \%)$ in $16-19$ years age group. The mean $( \pm S D)$ age of the mother at child birth was $24.85( \pm 5.66)$ years, while the age range was $16-40$ years. Maximum children (65.7\%) were of 1 st child and majority (81.1\%) children had primary level education (Table-II). On the basis of diagnosis of ASD in the children, maximum $(70.9 \%)$ children have noticed their first symptom at 2nd year and majority (47.4\%) children were diagnosed at the age of 3 years while the mean $( \pm S D)$ age of the child at diagnosis was $24.85( \pm 5.66)$ years. The study also shows that majority children $(77.1 \%)$ were diagnosed in different government hospitals followed by $(12.6 \%)$ in specialized schools, $(8.6 \%)$ in private hospitals, and $(12.3 \%)$ in private chambers of specialist doctor (Table-III). Figure-1 shows that, more than half $(53.1 \%)$ parents had low level and (46.9\%) had high level of stress. According to different scales like Wellness Scale of coping capacity, Thought Control Scale, Active Coping Scale, Social Ease Scale, Tension Reduction Scale and Spiritual Practice Scale most (98.3\%) parents were above average and only $(1,7 \%)$ were average stresscoper (Table-IV). According to Physical, Psychological, Social relationship and Environmental domain maximum parents were in average category of quality of life (Table-V).

In different domains the mean $( \pm S D)$ score of QoL were $53.04 \pm 9.38,46.12( \pm 9.14), 62.71( \pm 14.48)$ and $49.75( \pm 7.46)$ and the range of score of QoL was 32.14-78.57, 25.00-70.83, 25.00100.00 and $28.12-75.00$ respectively (Table-VI). Except physical domain, the quality of life was higher in low level of parental stress than in high level and these differences were statistically significant (Table-VII). Regarding coping capacity, in all domains parents with above average stresscoper were found having higher level of quality of life but the differences were statistically significant in physical and environmental domains (Table-VIII). According to level of parenting stress except in physical domain of quality of life, in all other domains the parents with low level 
of stress were under average category of different domains of QoL (Table-IX). In respect of level of coping capacity and different domains of QoL, maximum parents with average stresscoper were under poor category of QoL (Table-X).

Table-I: Distribution of the parents by socio-demographic characteristics $(n=175)$

\begin{tabular}{|c|c|c|c|}
\hline Attribute & Category & Frequency & Percentage \\
\hline \multirow{2}{*}{ Place of residence } & Urban & 163 & 93.1 \\
\hline & Periurban & 12 & 6.9 \\
\hline \multirow{2}{*}{ Type of family } & Single & 162 & 92.6 \\
\hline & Joint & 13 & 7.4 \\
\hline \multirow{3}{*}{ Numberof family member } & $2-4$ & 147 & 84.0 \\
\hline & $5-7$ & 28 & 16.0 \\
\hline & \multicolumn{3}{|c|}{ Mean \pm SD $3.85 \pm 0.81(2-7)$} \\
\hline \multirow{5}{*}{ Number of children } & 1 & 56 & 32.0 \\
\hline & 2 & 97 & 55.4 \\
\hline & 3 & 18 & 10.3 \\
\hline & 4 & 4 & 2.3 \\
\hline & \multicolumn{3}{|c|}{ Mean $\pm S D 1.83 \pm 0.70(1-4)$} \\
\hline \multirow{4}{*}{ Monthly family income (Taka) } & $12500-20000$ & 16 & 9.1 \\
\hline & $20001-50000$ & 110 & 62.9 \\
\hline & $50001-150000$ & 49 & 28.0 \\
\hline & \multicolumn{3}{|c|}{ Mean \pm SD $49020.45 \pm 31872.11$} \\
\hline \multirow{2}{*}{$\begin{array}{l}\text { Consanguineous marriage } \\
\text { between parents }\end{array}$} & Yes & 20 & 11.43 \\
\hline & No & 155 & 88.57 \\
\hline
\end{tabular}

Table II: Distribution of the children by socio-demographic characteristics $(n=175)$

\begin{tabular}{|l|l|c|c|}
\hline \multicolumn{1}{|c|}{ Attribute } & \multicolumn{1}{|c|}{ Category } & Frequency & Percentage \\
\hline \multirow{4}{*}{$\begin{array}{l}\text { Age of mother at birth of this child } \\
\text { (Years) }\end{array}$} & $16-19$ & 34 & 19.4 \\
\cline { 2 - 4 } & $20-29$ & 99 & 56.6 \\
\cline { 2 - 4 } & $30-40$ & 42 & 24.0 \\
\cline { 2 - 4 } & Mean \pm SD $24.85 \pm 5.66$ \\
\hline \multirow{4}{*}{ Birth order of the child } & First & 115 & 65.7 \\
\cline { 2 - 4 } & Second & 52 & 29.7 \\
\cline { 2 - 4 } & Third & 7 & 4.0 \\
\cline { 2 - 4 } & Fourth & 1 & 0.6 \\
\hline \multirow{3}{*}{ Education level of the child } & llliterate & 23 & 13.1 \\
\cline { 2 - 4 } & Primary & 142 & 81.1 \\
\cline { 2 - 4 } & Secondary & 10 & 5.7 \\
\hline
\end{tabular}

Table III: Distribution of the children by diagnosis of ASD $(n=175)$

\begin{tabular}{|l|l|c|c|}
\hline Attribute & \multicolumn{1}{|c|}{ Category } & Frequency & Percentage \\
\hline \multirow{4}{*}{$\begin{array}{l}\text { Age at first } \\
\text { symptom noticed } \\
\text { (Year) }\end{array}$} & 1 & 34 & 19.4 \\
\cline { 2 - 4 } & 2 & 124 & 70.9 \\
\cline { 2 - 4 } & 3 & 6 & 3.4 \\
\cline { 2 - 4 } & 4 & 11 & 6.3 \\
\hline \multirow{4}{*}{$\begin{array}{l}\text { Age at diagnosis } \\
\text { (Year) }\end{array}$} & 1 & 17 & 9.7 \\
\cline { 2 - 4 } & 2 & 45 & 25.7 \\
\cline { 2 - 4 } & 3 & 83 & 47.4 \\
\cline { 2 - 4 } & 4 & 30 & 17.1 \\
\cline { 2 - 4 } & Mean \pm SD 2.72 \pm 0.86 & 135 & 77.1 \\
\hline \multirow{4}{*}{$\begin{array}{l}\text { Place of } \\
\text { diagnosis }\end{array}$} & Government Hospital & 15 & 8.6 \\
\cline { 2 - 4 } & Private Hospital & 3 & 1.7 \\
\cline { 2 - 4 } & Private chamber of pecialist & 22 & 12.6 \\
\cline { 2 - 4 } & Specialized school & & \\
\hline
\end{tabular}

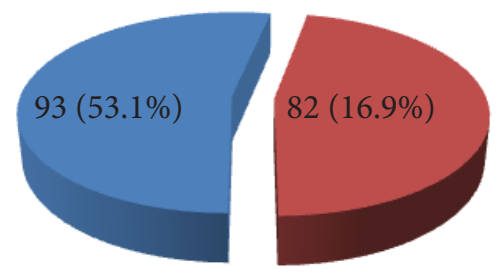

Low Level of stress

High Level of stress

Figure-1: Distribution of level of parental stress

Table- IV: Distribution of level of coping capacity of the parent $(n=175)$

\begin{tabular}{|c|c|c|c|}
\hline $\begin{array}{l}\text { Scale of coping } \\
\text { capacity }\end{array}$ & Category & Frequency & Percentage \\
\hline \multirow{3}{*}{ Wellness Scale } & Superior Stresscoper & 19 & 10.9 \\
\hline & Above Average Stresscoper & 155 & 88.6 \\
\hline & Average Stresscoper & 1 & 0.6 \\
\hline \multirow{3}{*}{$\begin{array}{l}\text { Thought Control } \\
\text { Scale }\end{array}$} & Superior Stresscoper & 7 & 4.0 \\
\hline & Above Average Stresscoper & 166 & 94.9 \\
\hline & Average Stresscoper & 2 & 1.1 \\
\hline \multirow{3}{*}{$\begin{array}{l}\text { Active Coping } \\
\text { Scale }\end{array}$} & Superior Stresscoper & 20 & 11.4 \\
\hline & Above Average Stresscoper & 148 & 84.6 \\
\hline & Average Stresscoper & 7 & 4.0 \\
\hline \multirow{2}{*}{$\begin{array}{l}\text { Social Ease } \\
\text { Scale }\end{array}$} & Superior Stresscoper & 40 & 22.9 \\
\hline & Above Average Stresscoper & 135 & 77.1 \\
\hline \multirow{4}{*}{$\begin{array}{l}\text { Tension } \\
\text { Reduction Scale }\end{array}$} & Superior Stresscoper & 89 & 50.9 \\
\hline & Above Average Stresscoper & 75 & 42.9 \\
\hline & Average Stresscoper & 8 & 4.6 \\
\hline & Below Average Stresscoper & 3 & 1.7 \\
\hline \multirow{4}{*}{$\begin{array}{l}\text { Spiritual Practice } \\
\text { Scale }\end{array}$} & Superior Stresscoper & 56 & 32.0 \\
\hline & Above Average Stresscoper & 93 & 53.1 \\
\hline & Average Stresscoper & 25 & 14.3 \\
\hline & Below Average Stresscoper & 1 & 0.6 \\
\hline \multirow{2}{*}{ Overall Scale } & Above Average Stresscoper & 172 & 98.3 \\
\hline & Average Stresscoper & 3 & 1.7 \\
\hline
\end{tabular}

Table-V: Distribution of the level of Quality of life

\begin{tabular}{|l|l|c|c|}
\hline \multicolumn{1}{|c|}{ Attribute } & Category & Frequency & Percentage \\
\hline \multirow{2}{*}{ Physical } & Poor & 51 & 29.1 \\
\cline { 2 - 4 } & Average & 124 & 70.9 \\
\hline \multirow{3}{*}{ Psychological } & Poor & 91 & 52.0 \\
\cline { 2 - 4 } & Average & 84 & 48.0 \\
\hline \multirow{3}{*}{ Envial relationship } & Poor & 25 & 14.3 \\
\cline { 2 - 4 } & Average & 140 & 80.0 \\
\cline { 2 - 4 } & Good & 10 & 5.7 \\
\hline \multirow{2}{*}{ Environment } & Poor & 74 & 42.3 \\
\cline { 2 - 4 } & Average & 101 & 57.7 \\
\hline
\end{tabular}


Table Vl: Distribution of score by different domains of quality of life of the parents $(n=175)$

\begin{tabular}{|l|c|c|c|}
\hline \multicolumn{1}{|c|}{ Domains } & Mean \pm SD & Minimum & Maximum \\
\hline Physical & $53.04 \pm 9.38$ & 32.14 & 78.57 \\
\hline Psychological & $46.12 \pm 9.14$ & 25.00 & 70.83 \\
\hline Social relationship & $62.71 \pm 14.48$ & 25.00 & 100.00 \\
\hline Environment & $49.75 \pm 7.46$ & 28.12 & 75.00 \\
\hline
\end{tabular}

Table VII: Mean \pm SD score of different domain of quality of life by level parental stress $(n=175)$

\begin{tabular}{|l|c|c|c|}
\hline \multirow{3}{*}{ Domains } & \multicolumn{2}{|c|}{ Level of parental stress } & \multirow{2}{*}{$\begin{array}{c}\text { Significance } \\
\text { (Student ' } t \text { ' test) }\end{array}$} \\
\cline { 2 - 3 } & Low level & High level & \multirow{2}{*}{ (Stun } \\
\cline { 2 - 3 } & Mean \pm SD & Mean \pm SD & \\
\hline Physical & $53.03 \pm 9.68$ & $53.05 \pm 9.09$ & $\mathrm{t}=0.011, \mathrm{df}=173 \mathrm{p}=0.992$ \\
\hline Psychological & $49.01 \pm 7.04$ & $42.84 \pm 10.13$ & $\mathrm{t}=4.729, \mathrm{df}=173 \mathrm{p}<0.001$ \\
\hline Social relationships & $66.22 \pm 10.67$ & $58.74 \pm 17.07$ & $\mathrm{t}=3.518, \mathrm{df}=173 \mathrm{p}=0.001$ \\
\hline Environment & $52.42 \pm 6.27$ & $46.72 \pm 7.57$ & $\mathrm{t}=5.442, \mathrm{df}=173 \mathrm{p}<0.001$ \\
\hline
\end{tabular}

Table-VIII: Score of different domain of quality of life by level coping capacity $(n=175)$

\begin{tabular}{|l|c|c|c|}
\hline \multirow{3}{*}{ Domains } & \multicolumn{2}{|c|}{ Level of coping capacity } & \multirow{2}{*}{$\begin{array}{c}\text { Significance } \\
\text { (Student ' } \mathrm{t} \text { ' test) }\end{array}$} \\
\cline { 2 - 3 } & $\begin{array}{c}\text { Above Average } \\
\text { Stress coper }\end{array}$ & $\begin{array}{c}\text { Average Stress } \\
\text { coper }\end{array}$ & \\
\cline { 2 - 3 } & Mean $\pm S D$ & Mean $\pm S D$ & \\
\hline Physical & $53.18 \pm 9.40$ & $45.24 \pm 2.06$ & $\mathrm{t}=5.713, \mathrm{df}=173 \mathrm{p}=0.006$ \\
\hline Psychological & $46.29 \pm 9.03$ & $36.11 \pm 12.03$ & $\mathrm{t}=1.928, \mathrm{df}=175 \mathrm{p}=0.055$ \\
\hline Social relationships & $63.08 \pm 13.99$ & $41.67 \pm 28.87$ & $\mathrm{t}=1.282, \mathrm{df}=173 \mathrm{p}=0.327$ \\
\hline Environment & $49.85 \pm 7.48$ & $43.75 \pm 0.00$ & $\mathrm{t}=10.704, \mathrm{df}=173 \mathrm{p}<0.001$ \\
\hline
\end{tabular}

Table-IX: Association between parental stress and level of quality of life $(n=175)$

\begin{tabular}{|c|c|c|c|c|}
\hline \multirow{2}{*}{ Attribute } & \multirow{2}{*}{ Category } & \multicolumn{2}{|c|}{ Level of parenting stress } & \multirow{2}{*}{$\begin{array}{c}\text { Significance } \\
\text { (Chi square test) }\end{array}$} \\
\hline & & Low level & High level & \\
\hline \multirow{2}{*}{ Physical } & Poor & $28(30.1) \#$ & $23(28.0)$ & \multirow{2}{*}{$\begin{array}{c}\chi^{2}=0.089, d f=1 \\
p=0.765\end{array}$} \\
\hline & Average & $65(69.9)$ & $59(72.0$ & \\
\hline \multirow{2}{*}{ Psych logical } & Poor & 32 (34.4) & $59(72.0)$ & \multirow{2}{*}{$\begin{array}{c}\chi^{2}=24.607, d f=1 \\
p=<0.001\end{array}$} \\
\hline & Average & $61(65.6)$ & $23(28.0)$ & \\
\hline \multirow{3}{*}{ Social relationship } & Poor & $4(4.3)$ & $21(25.6)$ & \multirow{3}{*}{$\begin{array}{c}\chi 2=22.816, d f=1 \\
p=<0.001\end{array}$} \\
\hline & Average & 87 (93.5) & $53(64.6)$ & \\
\hline & Good & $2(2.2)$ & $8(9.8)$ & \\
\hline \multirow{2}{*}{ Environment } & Poor & $20(21.5)$ & (65.9) & \multirow{2}{*}{$\begin{array}{c}\chi 2=35.118, d f=1 \\
p=<0.001\end{array}$} \\
\hline & Average & $73(78.5)$ & $28(34.1)$ & \\
\hline
\end{tabular}

Table-X: Association between coping capacity and level of quality of life $(n=175)$

\begin{tabular}{|c|c|c|c|c|}
\hline \multirow[b]{2}{*}{ Attribute } & \multirow[b]{2}{*}{ Category } & \multicolumn{2}{|c|}{ Level of coping capacity } & \multirow[b]{2}{*}{$\begin{array}{c}\text { Significance } \\
\text { (Fisher's Exact test) }\end{array}$} \\
\hline & & $\begin{array}{c}\text { Above } \\
\text { average } \\
\text { stress coper }\end{array}$ & $\begin{array}{c}\text { Average } \\
\text { stresscoper }\end{array}$ & \\
\hline \multirow{2}{*}{ Physical } & Poor & 48 (27.9)\# & $3(100.0)$ & \multirow{2}{*}{$p=0.024$} \\
\hline & Average & $124(72.1)$ & $0(.0)$ & \\
\hline \multirow{2}{*}{ Psychological } & Poor & $89(51.7)$ & $2(66.7)$ & \multirow{2}{*}{$p=0.999$} \\
\hline & Average & $83(48.3)$ & $1(33.3)$ & \\
\hline \multirow{3}{*}{ Social relationship } & Poor & $23(13.4)$ & $2(66.7)$ & \multirow{3}{*}{$p=0.102$} \\
\hline & Average & $139(80.8)$ & $1(33.3)$ & \\
\hline & Good & $10(5.8)$ & $0(.0)$ & \\
\hline \multirow{2}{*}{ Environment } & Poor & $71(41.3)$ & $3(100.0)$ & \multirow{2}{*}{$p=0.074$} \\
\hline & Average & $101(58.7)$ & $0(.0)$ & \\
\hline
\end{tabular}

\section{Discussion}

Autistic Disorder has been recently recognized as a major epidemic problem found in all racial and ethnic groups and across the socioeconomic continuum. It is considered one of the most complex childhood developmental disabilities that can devastatingly affect children's communication and social abilities. A substantial body of research has uniformly found that parenting a child with Autistic Disorder can disturb the whole family life and result in several economic, social, physical and psychological problems. Therefore, the quality of those parents' lives is placed in serious jeopardy. In fact, parents of children with Autistic Disorder have been found to experience significantly higher levels of parenting stress and psychological distress compared with parents of typical children and parents of children with other developmental disabilities ${ }^{8,9}$.

Evidence revealed that parents have to confront enormous parenting stress to rare and care their autistic children. For this they have to adopt diverse coping strategy to overcome that stress which influences their quality of life. Therefore, this study was conducted to assess the linkage between parenting stress and coping capacity with the levels of quality of life among reported parents. A total of 175 parents having children with autism spectrum disorder were included in this study. According to age, most of the parents $(93.7 \%)$ were $21-50$ years old and the mean $( \pm S D)$ ages of the parents were $37.75( \pm 8.04)$ years, while In this study, most (93.7\%) of the parents were Muslim and only $6.3 \%$ were Hindu. A study conducted by Khan in Dhaka found that $91.8 \%$ were Muslim and $8.2 \%$ were Hindu. Another cross sectional study was conducted by Rahman in Dhaka, Bangladesh and revealed that $91.3 \%$ parents were Muslim ${ }^{10}$. These findings are similar with the present findings. In all the studies, the highest number of respondents was Muslim because of predominance of Muslim population in Bangladesh ${ }^{10}$.

The range of age was 21-64 years. A study was conducted by $S$ Sandin in Denmark and revealed that couples ${ }^{9}$ of mothers 20-39 years of age and fathers $20-49$ years of age generated $94.6 \%$ of all births. In this study, almost similarly parents 21-50 years of old generated $93.7 \%$ of all births and only $6.3 \%$ birth were generated by 51-64 years of old parents ${ }^{9}$ (S Sandin). Regarding sex of the parents, more than half $(53.7 \%)$ was female and $46.3 \%$ were male with a female male ratio 1.16:1. A similar study conducted by Dardas LA in Jordan and revealed that out of 184 participants $61.96 \%$ were female ${ }^{2}$ and $38.04 \%$ were male with a female male ratio 1.6:1. In this study, the male participants were more in comparison with the study conducted in Jordan because of more awareness program and specialized schools are operated by government of Bangladesh. In Bangladesh, earlier due to stigma and lack of knowledge fathers used to ignore the responsibility of taking care of ASD children and hence mothers used to take care of them. Other than these, the difference in the present study was due to variation of data collection place ${ }^{2}$.

Regarding education of the parents, majority $(74.3 \%)$ were educated up to graduation and masters' level. A study conducted by Dardas LA in Jordan and revealed that more than half of the participants $(53 \%)$ had diploma ${ }^{2}$ or baccalaureate degree. This 
difference with the present study was due to place variation that is; all data were collected from the parents of autistic children of specialized schools of Dhaka city. There were no significant association between different levels of education with parenting stress, coping capacity, quality of life and overall quality of life ( $p>0.05)$, except, there was significant association with physical domain of quality of life, where this domain of quality of life was better among parents whose educational qualification was in graduation $^{2}$ level $(p<0.05)$.

In this study, maximum (72.0\%) fathers of ASD children were service holder followed by businessman $26.8 \%$. A study conducted by in Bangladesh revealed that maximum $(58.7 \%)$ fathers were service holder and $37.0 \%$ were business man $^{10}$. Another study was conducted by Khan in Dhaka city found that, $63.9 \%$ fathers were service holder ${ }^{11}$ and $29.5 \%$ were businessman. These study results are commensurate ${ }^{10}$ with the present study. According to mother's occupation, most $(83.43 \%)$ were housewives. A study conducted by in Bangladesh revealed that, most $(83.3 \%)$ of the mothers was housewife ${ }^{12}$. Another study conducted by in Dhaka revealed that maximum10 (81.5\%) mothers were house wife. These study findings are similar with the present study because socio cultural condition of Bangladesh hardly allowed women to work outside the home and fathers are the earning member of maximum families ${ }^{12}$.

Among all the parents, most (93.1\%) were from urban areas followed by $6.9 \%$ were from peri-urban areas. A study conducted by in Dhaka city found that majority $(75.0 \%)$ respondents were from urban area ${ }^{10}$. Another study conducted by in Bangladesh revealed that $53.3 \%$ mothers live in urban area, semi-urban area $33.3 \%$ and $13.3 \%$ rural area ${ }^{12}$. These differences are because of, in the present study all respondents were interviewed from special schools of Dhaka city. A study was conducted from January to April 2010 in mainland China found that $90 \%$ lived in urban areas, which is consistent with the present study as both the studies were conducted in capital cities ${ }^{13}$. According to the type of family, off the all, most (92.6\%) parents were from nuclear family and $7.4 \%$ were from joint family. A study conducted by in Dhaka city found that $72 \%$ were from nuclear family ${ }^{11}$. Another study conducted by in Bangladesh revealed that majority (76.1\%) were from nuclear family ${ }^{14}$. A descriptive cross sectional study from January to June, 2012 was conducted by in Dhaka City found $87 \%$ children were from nuclear families. These study results are a bit different with the present study because in last few decades rapid urbanization was the main reasons of demographic transition of Bangladesh. In the social context of this country father, mother and only their children used to live together separately years after years. As a result, the number of nuclear family ${ }^{14}$ was more. In this study, off all, $11.43 \%$ parents had history of consanguineous marriage ${ }^{10}$. A study conducted by in Dhaka showed $10.9 \%$ parents had history of consanguineous marriage, which is almost similar with the present study. Consanguineous marriage is thought to be one of the causes of developmental disorders. But very few studies have attempted to determine the current prevalence of consanguinity or its effects on population health ${ }^{15}$.
According to monthly family income, almost two third (62.9\%) parents had monthly family income Tk. 20001-50000 followed by Tk. $50001-150000$ (28.0\%) and Tk. $12500-20000$ (9.1\%). The mean monthly family income was Tk. 49020.45 with standard deviation \pm Tk. 31872.11 and the range was Tk. 12500-150000. There were no association and statistical significance between different levels of monthly family income with parenting stress, different domains of quality of life and overall quality of life $(p>0.05)$. Whereas, there was inverse correlation and statistical significance between monthly family income and coping capacity $(r=-0.217, p<0.01)$ among parents who had monthly family income of Tk. 20001-50000. In the present study, monthly family income is more because per capita income of Bangladeshi people has increased than previous years. A cross sectional study was conducted in China between May 2007 and August 2009 found that the annual average household income was 31880.00 RMB (Tk. 372,996 approx.). Monthly income of present study is more because the study of China was conducted few years back and overall socioeconomic status of China at that time was similar to present status of our country ${ }^{16}$.

According to birth order of the children, majority $(65.7 \%)$ were first born followed by $29.7 \%$ were second born, $4.0 \%$ were third born and $0.6 \%$ were fourth born. A descriptive cross sectional study was conducted by in two autism schools in Dhaka City ${ }^{14}$, Bangladesh from January to June, 2012 revealed that the birthorder of the child was important as $58 \%$ of children were first born and $33 \%$ were second born, whereas $7 \%$ and $2 \%$ were third and fourth born respectively $(p<0.001)$. The result of this study is consistent with the present study. In the present study, off all, more than two third (70.9\%) children have noticed their first symptom ${ }^{14}$ at $2^{\text {nd }}$ year of age. There is currently no medical test to diagnose autism. Rather, autism is diagnosed by observing a child's behavior and looking for specific symptoms. Researchers have been studying the earliest signs of autism in babies and toddlers so that doctors know what to look for and so that children can get the help they need as soon as possible. By looking back at the home videotapes of young children with autism, some early symptoms have become apparent. Furthermore, because the younger siblings of children with autism are at increased risk ( 6 to $9 \%$ ) of developing autism themselves, researchers have studied these siblings and been able to track the development of autism from infancy. What has evolved is a list of early "red flags" or signs of autism that can be seen in children between 12 and 18 months of age. This is similar with the present study. According to the children's age at diagnosis of ASD, out of all, almost half of the children (47.4\%) were diagnosed at the age of 3 years with mean $( \pm S D)$ age of diagnosis was $2.72 \pm 0.86$ years while the range was 1-4 years. Despite increased awareness, many children are still not diagnosed with autism until at least age four ${ }^{17}$ or when they are much older ${ }^{18}$.

Since we know that early intervention improves outcomes for most young children with autism, detecting autism as early as possible is essential. It is expected that providing therapy at a very young age, when a child's brain development is most receptive to learning, can alter the course of autism. A study conducted by and revealed there is increasing evidence that diagnosis in the second year of life is possible in some children. 
Early diagnosis will lead to earlier behavior-based intervention, which is associated with improvements in core areas, such as social functioning and communication. Early detection of-and intervention to treat-ASD is crucial because it is likely to lead to an improved outcome. Early diagnosis of autism spectrum disorders (ASD) is critical for a number of reasons ${ }^{19}$ perhaps most important because interventions to improve the functioning of children with ASD may be more effective with younger children. Evidence suggests that early treatment optimizes long-term prognosis and treatment yields diminishing returns as children get older. Several studies have estimated that the gains in functioning associated with early treatment will result in considerable cost savings to both families of children with ASD and the systems in which they are served. According to the present study, out of all the children, majority $(77.1 \%)$ were diagnosed in government hospital followed by specialist doctors' chamber $1.7 \%$,

private hospital $8.6 \%$ and private clinic (12.6\%). Highest numbers of children were diagnosed in government hospital because recently government of Bangladesh has taken lot of initiatives to provide diagnostic facilities of ASD children in tertiary level government hospitals especially in Dhaka and treatment costs in these government hospitals were also less than specialist chamber and private hospitals. Besides these, paediatric neurologist, psychologists, diagnostic and other facilities were available mainly in government hospitals. Regarding source of treatment of ASD children, out of all $60.6 \%$ were treated by specialist doctor followed by MBBS doctor $37.7 \%$ and special school $1.7 \%$.

The government of Bangladesh and few private organizations are continuing awareness program since last decades. Maximum $(96.8 \%)$ children were treated initially by specialist doctors because now specialist doctors are available in all levels of healthcare facilities mainly in district hospitals and parents expect early diagnosis and better treatment. A significant number of children (10.4\%) were treated by specialist school because these schools also have facilities for diagnosis and treatment of ASD. Now days, the MBBS doctors are much aware about diagnosis and providing proper guidelines about ASD children. So, initial reporting and diagnosis of ASD children at chamber of MBBS doctors has increased many folds. Among all the children, most $(81.1 \%)$ of them used speech therapy followed by occupational therapy $(60.0 \%)$. A study conducted by in USA ${ }^{20}$ and indicated that, speech therapy being the most common service for children diagnosed with autism as $87.3 \%$ of families utilized this source followed by occupational therapy with $67.5 \%$ of families utilizing this source. A combined telephone and self-administered survey was completed by 301 families with a child, 8 years old or younger, in North Carolina, USA revealed, $83 \%$ of families used speech ${ }^{21}$ and language therapy, $64 \%$ of families used occupational therapy, $28 \%$ used social skills training, and $11 \%$ used physical therapy. Picture exchange communication was used by $23 \%$ of families outside of the home and $21 \%$ used sensory integration therapy outside the home. Thirty percent of families used parent support groups and only $4 \%$ used family counseling.

These results are almost consistent with the present study and few deviations are due to understanding, knowledge and socio-economic difference between Bangladesh and USA ${ }^{22}$. A qualitative research was conducted. According to level of parenting stress, the study revealed that, out of all parents more than half $(53.1 \%)$ had low level of stress and $46.9 \%$ had high level. A Study based on Northern India shown the frequencies of the level of stress that is undergone by the parents of the autistic children, out of 320 parents, only $3.1 \%$ parents were in normal range and rest $(96.9 \%)$ had different level of stress. Another study was conducted by Abidin RR revealed that most of the parents ${ }^{23}(81.3 \%)$, were having high level of Stress and $15.6 \%$ parents were in the risk range. In this study only two level of stress have been identified by using PSI-SF scale and all the parents (100\%) had either high or low level of stress. Parenting an autistic child is undoubtedly a big challenge. Particularly a country like Bangladesh where lack of education and poverty acts as a barrier for addressing this issues and there by parents need to encounter different level of stress. Moreover, this difference was due to using different scale and socioeconomic condition (Abidin RR). According to level of parenting stress except in physical domain of quality of life, in all other domains the parents with low level of stress were under average category of different domains of QoL. In respect of level of coping capacity and different domains of QoL, maximum parents with average stresscoper were under poor category of QoL.

\section{Conclusion}

Autism is characterized by the coexistence of impaired social relations and communication with restricted and repetitive patterns of behavior. This study intended to find out the parenting stress and coping capacity link with quality of life among parents of children with ASD. To improve quality of life, measures for reduction of parenting stress and strategy for coping capacity needed through timely noticing of symptoms, early diagnosis, proper treatment and rehabilitation. To encounter different level of parenting stress proper education and poverty alleviation program should be taken by government and NGOs. The study recommended comprehensive studies should be conducted to explore realistic scenario about link between parenting stress and coping capacity with quality of life among parents of autism spectrum disorder,

\section{References}

1. Stephanie A Hayes. The impact of parenting stress: A meta analysis of studies Comparing the experience of Parenting stress in parents of children with and without Autism spectrum Disorder. University of Alberta, Canada (Thesis) 2012.

2. Dardas LA. Stress,Coping Strategies,and Quality of life among Jordanian Parents of Childern with Autistic Disorder. Autism 2014; 4:127. doi:10.4172/2165-7890.1000127.

3. World Health Organization. Meeting Report: Autism spectrum disorders \& other developmental disorders. From raising awareness to building capacity. Geneva. Switzerland. 16-18 September 2013.

4. The Daily Star. (2012). Autistic children: Gifts of God. Available at: http://archive.thedailystar.net/newDesign/news-details. php?nid=228999. Accessed on: 25 May 2015 at 1100 hours. 
5. Ministry of Health \& Family Welfare (MOHFW). (2014). Actions speak louder than words: Bangladesh's Unique Approach to Addressing the Public Health Challenge of Autism Spectrum Disorders.

6. bdnews24.com. WHO taking autism more seriously. Available at: http:// bdnews24.com/ health/2012/09/07/who-taking-autism-more-seriously.

7. Zerin SA. Fostering inclusive education. The Daily Star 2015. Available at: https:/www.thedailystar.net/fostering-inclusive-education-23813.

8. Autism spectrum Disorder. American Psychiatric Association (APA). In Diagnostic and Statistical Manual of Mental Disorders. Fifth Edition. American Psychiatric 2013. Vol.299.00.NO.F84.0.

9. S Samdin. Autism risk associated with parental age and with increasing difference in age between the parents. Denmark. (Thesis) 2016.

10. Rahman AKM. Health care seeking behavior of the parents for their autistic children, Armed Forces Medical Institute. Dhaka cantonment 2013.

11. Khan JH. Role of parents in meeting the educational needs of children with autism. Armed Force Medical Institute. Dhaka cantonment, Dhaka, (Thesis) 2014.

12. Nahar N. Level of depression of mothers of children with autism spectrum disorders. CRP-Bangladesh Repository. Centre for the Rehabilitation of the Paralysed (CRP), 2015. Retrieved from:http://202.4109.124:8080.

13. Sun $X$ Allson $C$, Auyeung $B$ et al. Service provision for autism in mainland China:Preliminary mapping of service pathways. Soc Sci Med 2013; 98:87-94.

14. Hasnain MG, Akter M. The Relation of Socio-economic Factors with Autism among Children: A Study in an Urban Area of Bangladesh. J Pioneer Med Sci 2014; 4(1):11-3.
15. Eapen V \& Guan J. Parental Quality of life in Autism Spectrum Disorder: Current status and Future Directions. Acta Psychopathologica 2016; 2:5. doi: 10.4172/2469-6676.100031.

16. Wang J, Zhou X, Xia W et al. Parent-reported health care expenditures associated with autism spectrum disorders in Heilongjiang province, China. BMC Health Services Research 2012; 12(1):7.

17. Sussman F. More than words: Helping parents promote communication and social skills in children with autism spectrum disorder. Toronto: The Haner centre.

18. Blumberg S. Changes in prevalence of parent-reported autism spectrum disorder in school-aged US Children. National Health statistics Reports 2013; 65:1-12.

19. Mandell Ds. Race differences in the age at diagnosis among Medicaideligible children with autism. J Am Acad Child Adolesc Psychiatry 2002; 41(12):1447-53

20. MacFartane JR and Kanaya T. What does it mean to be autistic? Inter-state variation in special education criteria for autism services. Journal of Child and Family Studies 2009; 18(6):662-9.

21. Thomas KC, Morrissey JP and McLaurin C. Use of autism-related services by families and children, Journal of Autism and Developmental Disorders 2007; 37(5):818-29.

22. Rahman T. The impacts of school based Occupational Therapy intervention for children with Autism: the mother's esperiences, Bangladesh Health Professions Institute (BHPI). Faculty of Medicine. Affiliated by University of Dhaka, March 2015.

23. Abidin RR. Parenting Stress Index (3rd ed), 1995, Odessa, FL:Psychological Assessment Resources. 